Journal of Engineering and Applied Sciences 14 (13): 4331-4346, 2019

ISSN: $1816-949 \mathrm{X}$

(C) Medwell Journals, 2019

\title{
Visualization of Integrating Hybrid Wind-PV Systems into Power Grid Using HVDC Link
}

\author{
${ }^{1,2}$ Gamal M.A. Sowilam, ${ }^{1,3}$ Tamer A. Kawady and ${ }^{1}$ Raed A. Shalwala \\ ${ }^{1}$ Department of Electrical Engineering, Faculty of Engineering and Islamic Architecture, \\ Umm Al-Qura University, Mecca, Saudi Arabia \\ ${ }^{2}$ Department of Electrical Power and Machine Engineering, \\ Faculty of Engineering, Helwan University, Helwan, Egypt \\ ${ }^{3}$ Department of Electrical Engineering, Faculty of Engineering, \\ Minoufiya University, Shibin E1 Kom, Egypt
}

\begin{abstract}
This study presents explores deeply the possibilities and benefits of interconnection of large Photo-Voltaic (PV) and wind power systems into the grid through High Voltage Direct Current (HVDC) link. The use of HVDC is usually required for transmission distance longer than $50 \mathrm{~km}$. Such lines are typically used to interconnect two asynchronous networks even with different frequencies to avoid possible stability disturbances greatly. A Maximum Power Point Tracking (MPPT) techniques is utilized to control the photovoltaic system in order to obtain the maximum power from the integrated PVs. Adapting the MPPT control changes the duty ratio of the boost converter and increase (or decrease) the output DC voltage of the PV power plant. Wind systems uses the MPPT through controlling the trip-speed ratio. In this study, a HVDC link with two 12-pulse converters based on thyristor-bridges for both rectification and inversion modes, respectively. The roles of the delay and the extinction angles of both the rectifiers and inverter are explored for controlling the transmitted active power from the PV and wind power plants into the grid. Different simulation investigations are provided with a detailed modeling with the Simulink/MATLAB for evaluation purposes. These tests corroborate the efficacy of HVDC links for supporting the integration of large PV and wind power plants into electrical grids.
\end{abstract}

$\underline{\text { Key words: PV power plant, wind turbines, HVDC link, PWM inverter, DC boost choppers, electrical grids }}$

\section{INTRODUCTION}

As known, renewable energy resources are clean, affordable, domestic and effectively infinite. Since, they have no emissions, they result in a clean and healthy environment for human beings. Other social outcomes are also gained by renewable power industries supporting economics well by creating more jobs that may help to stimulate local economies for their needs. Hence, renewable power plants have amazing worldwide growth with a global installation with more than 400 and $550 \mathrm{GW}$ for PV and wind power plants, respectively. Surprisingly, China has more than 78 and $160 \mathrm{GW}$ of PV and wind power plants now a days. Similarly, Germany has more than 40 and 50 GW of both power plant types, respectively. For Saudi Arabia in particular, a $16 \mathrm{GW}$ of grid-integrated $\mathrm{PV}$ power plants is a national target up to 2032 (Ackermann, 2005; Da Rosa, 2009).

With this increasing penetration levels of both power plants, hybrid solar and wind energy systems arise as a promising solution to provide reliable and efficient power resources with improved network efficacy and reduced storage requirements for both grid-integrated or standalone applications. However, such power plants may have some complexities in sizing, optimization or control processes with the continuous profile changes of their generated power due to the unexpected variations of the corresponding solar radiation and wind speed. Hence, integrating such power plants to the transmission (or sub-transmission) level with HVDC links may facilitate a preferable choice to eliminate the possible serious problems regarding the stability and power control issues (Markvart and Castaner, 2003; Yao et al., 2017). The HVDC link is considered as an asynchronous link and hence, any the connected AC supply through the converter won't to be synchronized with the link. Since, the DC link does not face any stability issues, those $\mathrm{AC}$ power plants with different frequency systems can be easily interconnected through HVDC links without being synchronized (Rashid, 2001).

Corresponding Author: Gamal M.A. Sowilam, Department of Electrical Engineering,

Faculty of Engineering and Islamic Architecture, Umm Al-Qura University, Mecca, Saudi Arabia 
The major components of an HVDC transmission systems are the converter stations at the ends of the transmission system. In typical two-terminal transmission systems, a rectifier and an inverter are essentially required. The role of both stations can be reversed as required by the controllers at both terminals. The major components of a typical 12-pulse bipolar and back to back HVDC converter station (Rashid, 2001).

By Yao et al. (2017) capacity configuration and coordinated operation of a hybrid wind farm with FSIGbased and PMSG-based wind farms during grid faults IEEE trans. Energy convers. 2017, 32, 1188-1199 (Gao et al., 2017). In order to optimize the operation of such offshore units, the adjustment of reactive power set points for the corresponding wind turbine generators must be optimized to realize minimum losses within the wind farm and the HVDC transmission system and consequently obtain the maximum generated power. Karlis and Dokopoulos (1996) presented a simulation study and an experimental verification of the dynamic behavior of small autonomous power systems with alternative power sources including wind turbines, hydroelectric and PVs. Actually, combining hydroelectric power plants and diesel generators is of great interest due to the different changes of power rates. To realize an effective integration of the PV devices into the utility grid, a method for controlling the inverter operation was proposed by Karlis and Dokopoulos (1996) where the power demand from the network is monitored to adjust the angle and the magnitude of the inverter voltage aiming to improve the power quality and stability of the interconnected system.

By Carbone (2009) visualized the efficacy of using energy storage in grid-connected PV plants using experimental measurements. Energy storage by means of distributed batteries can improve the energy production of grid-connected PV power plants even with the varying operating conditions. This represents a possible alternative to other solutions for these issues such as utilizing distributed active MPPT units based on DC/AC or DC-DC power electronic converters connected in cascaded to each modular component of the PV plants. Batteries have been proposed to be in parallel with the proper number of modular components of the whole PV elements.

By Hosseini et al. (2011) presented an integrated system comprising of a PV array, a Fuel Cell (FC) stack and a battery set as input power sources in a unified structure using a new three-input DC-DC boost converter with a grid connected inverter. Hence, each switching cycle of the proposed boost converter is divided into five switching periods in comparison with the conventional structure. These switching periods introduce five different duty ratios for the proposed boost converter. Since, the summation of these duty ratios should be equaled to one as seen in the aforementioned paper, realizing a high level output voltage at the DC-link is not possible in this condition. This limitation of the duty ratios should be avoided by the control signals independently.

Alatrash et al. (2012) visualized the intermittent nature PV systems referring to the stability challenges to the distribution grid. The integration of ancillary services into Distributed Generation (DG) inverters is an effective approach to eliminate the corresponding challenges with intermittency. Petra solar's Generator Emulation Controls (GEC) technology equips DG inverters with voltage support through Volt/VAR droop, Low-Voltage RideTrough (LVRT) and micro grid forming capabilities. The study focused on demonstrating these features for stabilizing the output voltage and minimizing the resulting flicker due to PV intermittency and confused tripping using a laboratory-scale test bed based on a simplified $12 \mathrm{kV} / 10$ MVA feeder that were scaled down to its single-phase $120 \mathrm{~V} / 5 \mathrm{kVA}$ on its per-unit basis. Sowilam et al. (2014) presented an interconnection between two variable frequency systems wind farm in Al-Zafarana-Egypt and another grid $(50-60 \mathrm{~Hz})$ using HVDC links (monopolar and bipolar). A simulation study was performed based on real data and real configuration of Al-Zafarana-Egypt and interconnected to the grid $(220 \mathrm{kV}-60 \mathrm{~Hz})$ through a bipolar link HVDC as a case study. Sowilam et al. (2014) tried to adjust the firing angle of rectifier valves $(\alpha)$ and extinction angle of inverter $(\gamma)$ where the minimum firing angle control, minimum extinction angle control and constant current control were implemented for this target.

This study visualizes a practical viewpoint of interconnecting a hybrid PV-wind power plant to the grid through a multi-terminal bipolar HVDC link. Both the wind and PV systems are connected at the rectifier stations and the grid system is connected at the inverter system. The simulation of wind system and photovoltaic system will be modeled and tested. An efficient MPPT procedure is applied for both power systems. The variation of the firing and extinction angle angles on the power follow is characterized. All simulation tests are prepared using the Simulink/MATLAB programs.

\section{MATERIALS AND METHODS}

Proposed system description: Figure 1 shows the proposed hybrid $\mathrm{PV}$-wind power plant. Line-commutated bipolar multi-terminal converters comprises the utilized HVDC link where PV sub-system is connected to the 

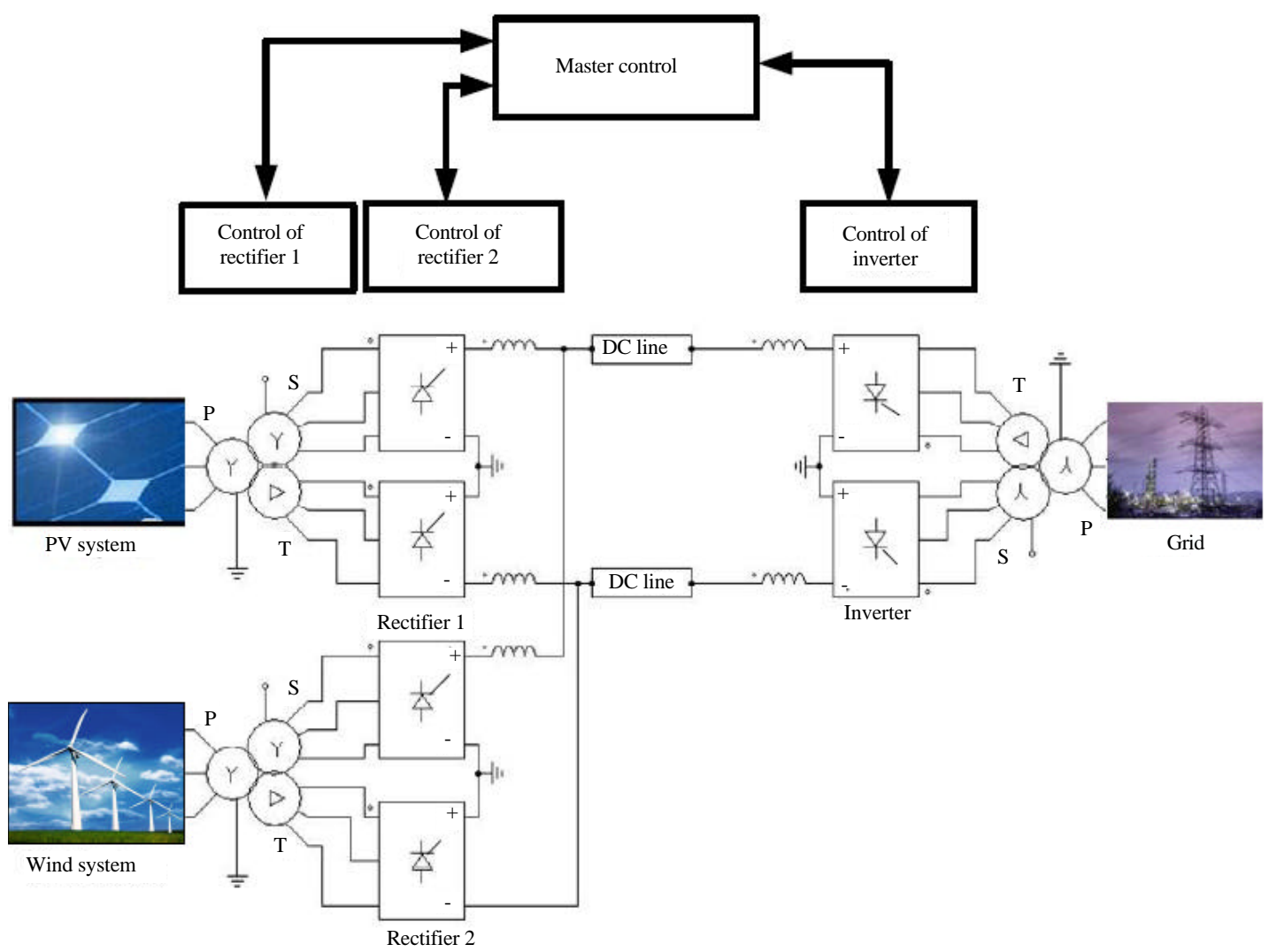

Fig. 1: Schematic of the proposed hybrid PV-wind power system

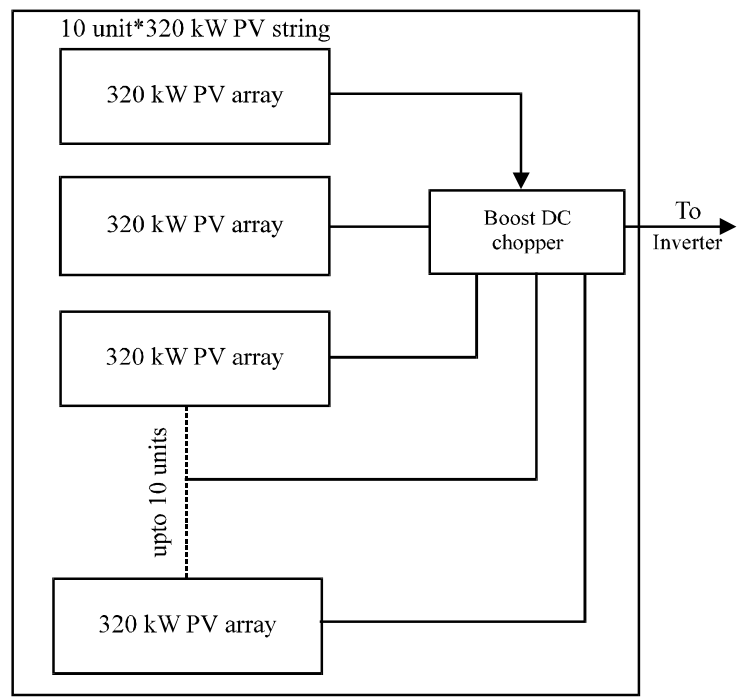

Fig. 2: Adopted 3.2 MW PV string

rectifier station 1 and the wind sub-system is connected to rectifier station 2. Both generation sub-systems operate at a frequency of $50 \mathrm{~Hz}$ while the utilized inverter station works at $60 \mathrm{~Hz}$.

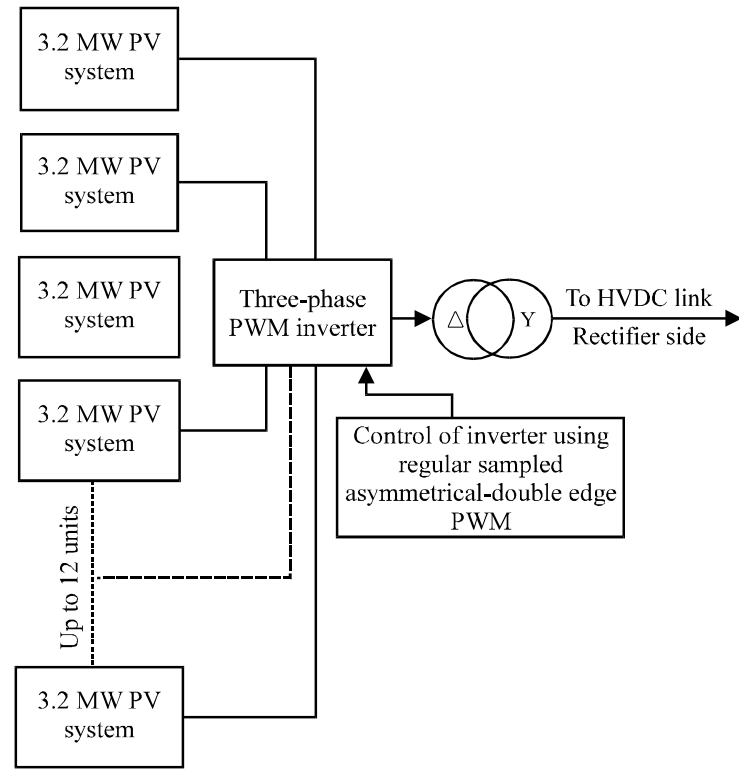

Fig. 3: Overall 38.4 MW PV sub-system

A typical $3.2 \mathrm{MW}$ PV strings with 10 unit of a $320 \mathrm{~kW}$ array is connected as described in Fig. 2 and 3 with the 


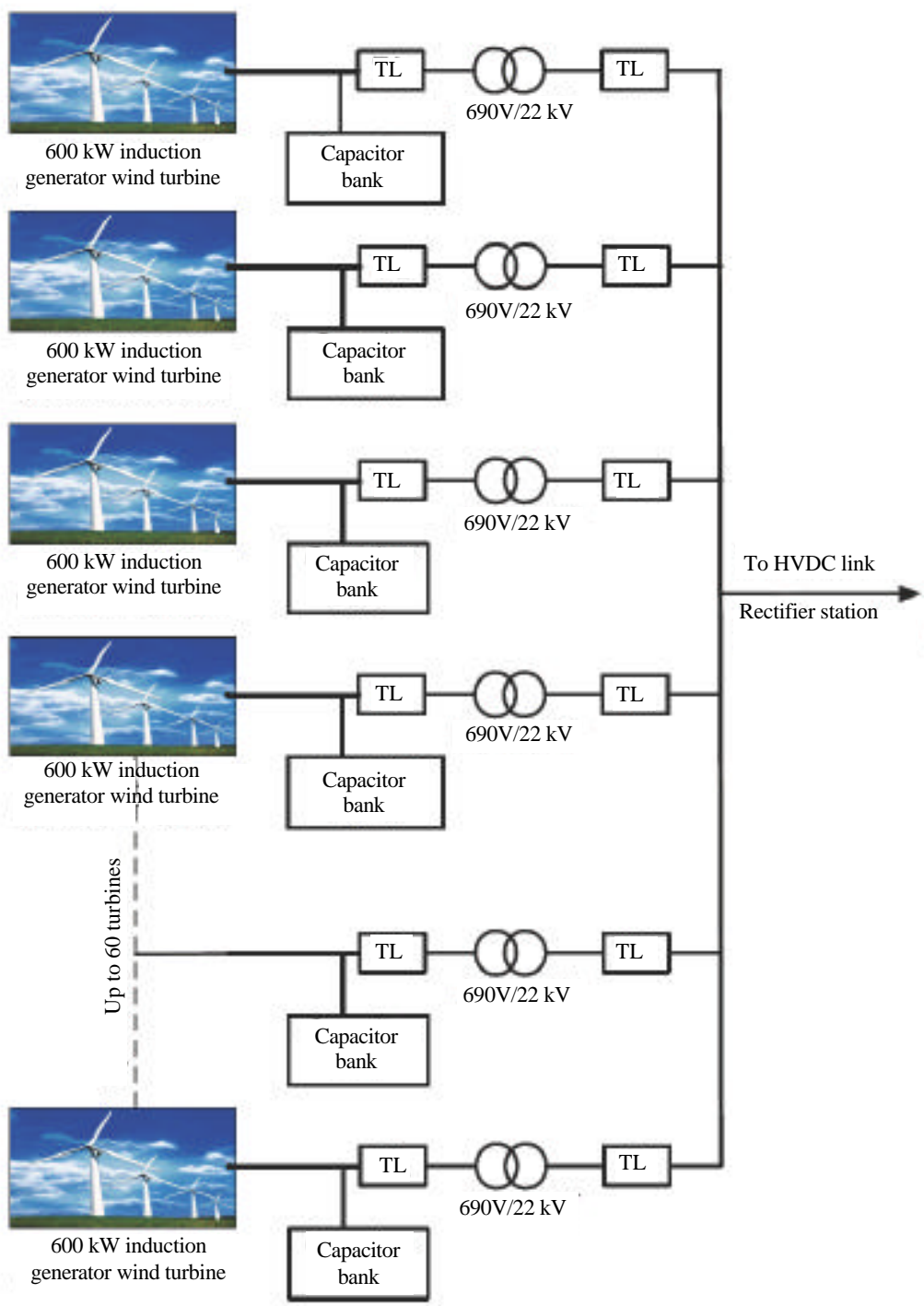

Fig. 4: Selected $36 \mathrm{MW}$ wind energy system

parameters listed in appendix. A boost DC chopper is utilized with each $320 \mathrm{~kW} \mathrm{PV}$ array. In order to obtain the maximum power from each PV array, all boost converters are controlled with a MPPT technique. Figure 3 shows the complete simulated PV sub-system consisting of twelve units of the $3.2 \mathrm{MW}$ string to obtain a maximum power of 38.4 MW. Then the overall 38.4 PV plant is connected to a central PWM inverter which is controlled with regular sampled asymmetrical-double edge PWM technique (Ahmed et al., 2005). The modulation frequency is selected to be $50 \mathrm{~Hz}$ with a frequency ratio of 33 and the modulation depth of 0.95 . The output of the inverter is connected to the HVDC link through a step-up transformer (rectifier station 1).

The selected $36 \mathrm{MW}$ wind sub-system is described is Fig. 4 with the parameters listed in appendix. It consists

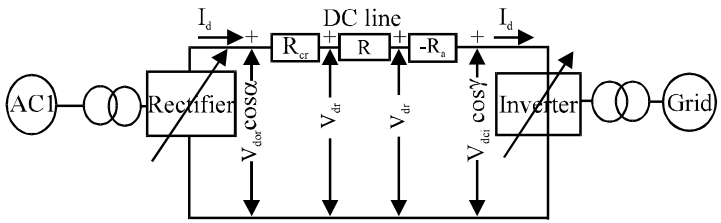

Fig. 5: Description of the adopted two terminal DC network

of 60 wind turbines where each one is equipped with a $600 \mathrm{~kW}$ induction generator with self excitation and capacitor back. All them connected to HVDC link (rectifier 2). As mentioned in PV system, the cumulated power are collected from each distributed unit and fed together to the rectifier station 2 (Fig. 5). The HVDC link consists of the rectifier unit, the 
DC line and the inverter unit as described earlier in Fig. 1. The converter unit is composed of two 6-pulse converter connected in series. Both series converters at the rectifier station are connected via. a smoothing reactor while other two series units are in opposite polarities to form the inverter station. Each converter is supplied through a three winding transformer with Y-earthed primary and both secondary's are of $\mathrm{Y}$ and $\Delta$ connection, respectively. These transformers act as a $30^{\circ}$ phase shift $\mathrm{AC}$ voltage of the secondary sides between the $\mathrm{Y}$ and $\Delta$ sides to produce the required 12-pulse rectifier system. Also, it boosts the average output voltage more than the monopolar-link (Sowilam et al., 2014). In order to reduce the ripples and the 5, 7,11 and 13th harmonics contents that are accompanied with the voltage waveform, dedicated filters can be used. The ratings of the rectifier station transformer is $40 \mathrm{MVA}, 50 \mathrm{~Hz}$ and $22 / 220 / 220 \mathrm{kV}$ while the grid is with $220 \mathrm{kV}$ and $60 \mathrm{~Hz}$. The length of HVDC link is 100 $\mathrm{km}$.

HVDC link control: A two terminal DC link is shown in Fig. 5 with a rectifier and an inverter stages. The DC system is represented by an inductance $\mathrm{L}$ and a line Resistance $\mathrm{R}$. The value of the inductance $\mathrm{L}$ comprises the smoothing reactor (s) and the DC line inductance whereas the value of $\mathrm{R}$ includes the accumulated resistance of the smoothing reactor (s) and the resistance of the DC line. Using Ohm's law, the DC current in the DC link depicted in Fig. 4 is given by Eq. 1:

$$
I_{d}=\frac{V_{d r}-V_{d i}}{R}
$$

Where:

$\mathrm{V}_{\mathrm{dr}}=$ DC-Voltage output of the rectifier

$\mathrm{V}_{\mathrm{di}}=$ DC-Voltage output of the inverter

$\mathrm{R}=$ The DC line Resistance

Then, the power at rectifier side of DC link is given by:

$$
\mathrm{P}_{\mathrm{dr}}=\mathrm{V}_{\mathrm{dr}} \mathrm{I}_{\mathrm{d}}
$$

The power at rectifier side of DC link is computed as:

$$
\mathrm{P}_{\mathrm{di}}=\mathrm{V}_{\mathrm{di}} \mathrm{I}_{\mathrm{d}}
$$

From converter theory, the relationship $\mathrm{V}_{d}-\mathrm{I}_{\mathrm{d}}$ for a rectifier is given by:

$$
\mathrm{V}_{\mathrm{dr}}=\mathrm{V}_{\mathrm{dor}} \cos \alpha-\mathrm{R}_{\mathrm{cr}} \mathrm{I}_{\mathrm{d}}
$$

From the converter theory, the relationship $V_{d}-I_{d}$ for an inverter is given by:

$$
\mathrm{V}_{\mathrm{di}}=\mathrm{V}_{\mathrm{doi}} \cos \gamma-\mathrm{R}_{\mathrm{ci}} \mathrm{I}_{\mathrm{d}}
$$

where, $R_{c r}$ and $R_{c i}$ depend on the overlap angles at rectifier and inverter, respectively. If the overlap angles is zero, their associated voltage drop equal to zero with overlap angles of 3 and $3 \mathrm{X}_{\mathrm{ci}} \mathrm{I}_{\mathrm{d}} / \pi$ for $\mathrm{R}_{\mathrm{cr}}$ and $\mathrm{R}_{\mathrm{ci}}$, respectively. $\mathrm{I}_{\mathrm{d}}$ is the $\mathrm{DC}$ current. $\mathrm{X}_{c r}$ is the commutation reactance of the HVDC transformer of the rectifier whereas $\mathrm{X}_{\mathrm{ci}}$ is commutation reactance of the inverter.

$\mathrm{V}_{\text {dor }}$ (with a limit of $1.35 \mathrm{~V}_{\mathrm{Lr}}$ ) is the maximum DC voltage of rectifier with firing angle $\alpha=0$ and $V_{L r}$ is the rms value of line input voltage of the rectifier while $V_{\text {doi }}$ (with a limit of $1.35 \mathrm{~V}_{\mathrm{Li}}$ ) is the maximum DC voltage for inverter with $\gamma=0$ and $\mathrm{V}_{\mathrm{Li}}$ is the rms value of line input voltage of the inverter.

Using the aforementioned equations for $\mathrm{V}_{\mathrm{dr}}$ or $\mathrm{V}_{\mathrm{di}}$, the DC line current can be estimated depending upon the choice of the control mode at the inverter. The DC current can be written as:

$$
\mathrm{I}_{\mathrm{d}}=\left(\mathrm{V}_{\mathrm{dor}} \cos \alpha-\mathrm{V}_{\mathrm{doi}} \cos \gamma\right) /\left(\mathrm{R}_{\mathrm{cr}}+\mathrm{R}-\mathrm{R}_{\mathrm{ci}}\right)
$$

Depending on $\mathrm{V}_{\text {dor }}, \mathrm{V}_{\text {doi }}, \alpha, \gamma$ and the DC current, the DC output power of the rectifier and inverter can be computed as:

$$
\begin{aligned}
& P_{d r}=V_{d o r} I_{d} \cos \alpha-R_{c r} I_{d}^{2} \\
& P_{d i}=V_{d o i} I_{d} \cos \gamma-R_{c i} I_{d}^{2}
\end{aligned}
$$

Since, there is no reactive power inside HVDC link, fixed capacitors and filters are utilized at each $\mathrm{AC}$ side to supplement the reactive power as mentioned before. Ideally, $\gamma$ should be selected to equal to $180-\alpha$ to reduce the voltage drop between the output of the rectifier and the input of inverter inside the HVDC link.

\section{RESULTS AND DISCUSSION}

Simulated test results: The overall test system comprising the hybrid PV-wind power plant and the related HVDC link was constructed in Simulink/MATLAB depending on its massive and detailed modeling library. Different tests were considered as summarized as follows:

- $\quad$ Fixed $\alpha, \gamma$ and PV irradiance and wind speed

- Sudden change in $\alpha$ while the rest parameters are constant 

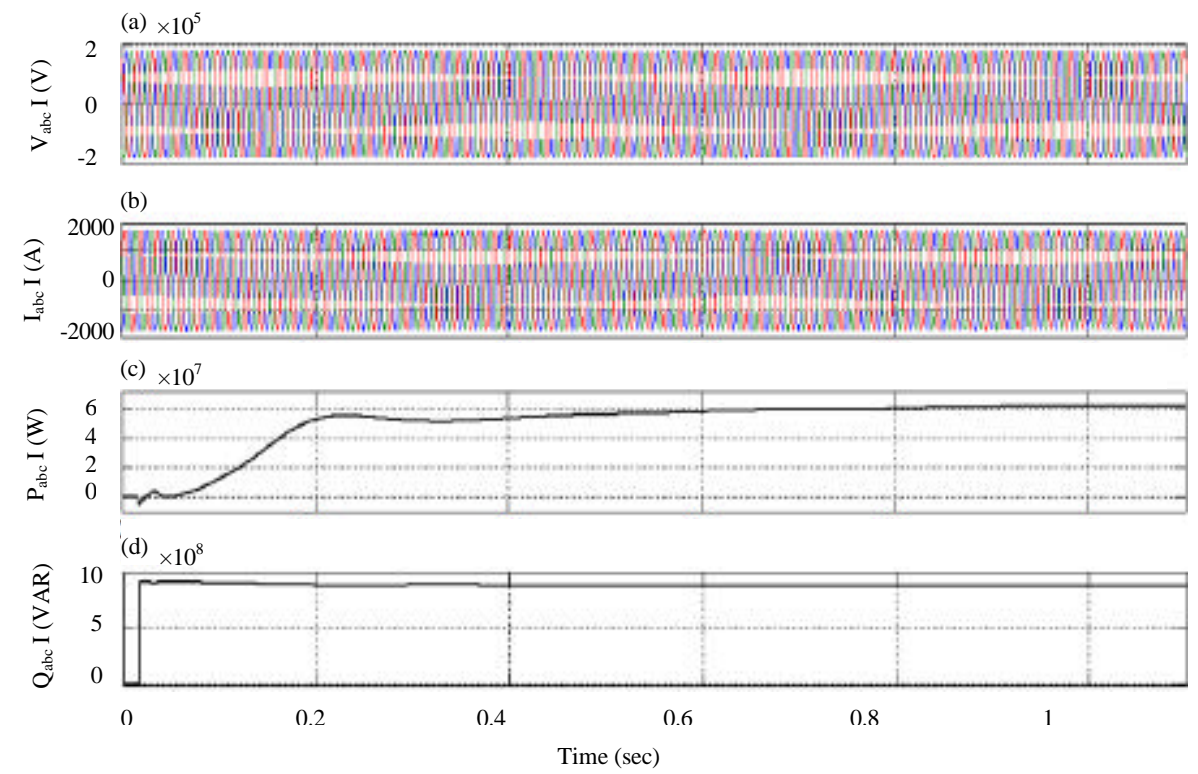

Fig. 6a-d): System performance at the inverter station (grid side) with a solar irradiance of $1000 \mathrm{~W} / \mathrm{m}^{2}$, wind speed of $9.5 \mathrm{msec}, \alpha=30^{\circ}$ and $\gamma=150^{\circ}$

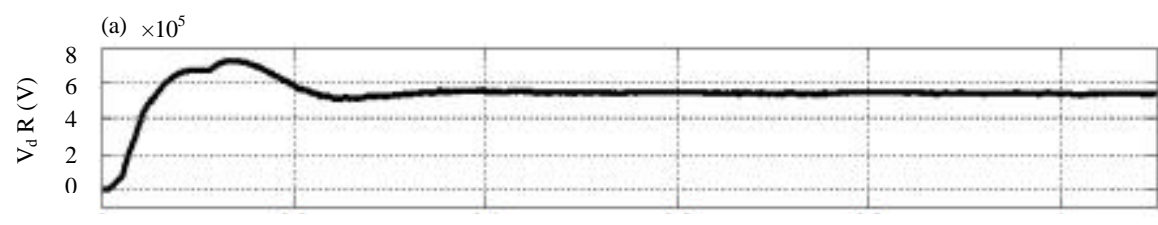

(b)
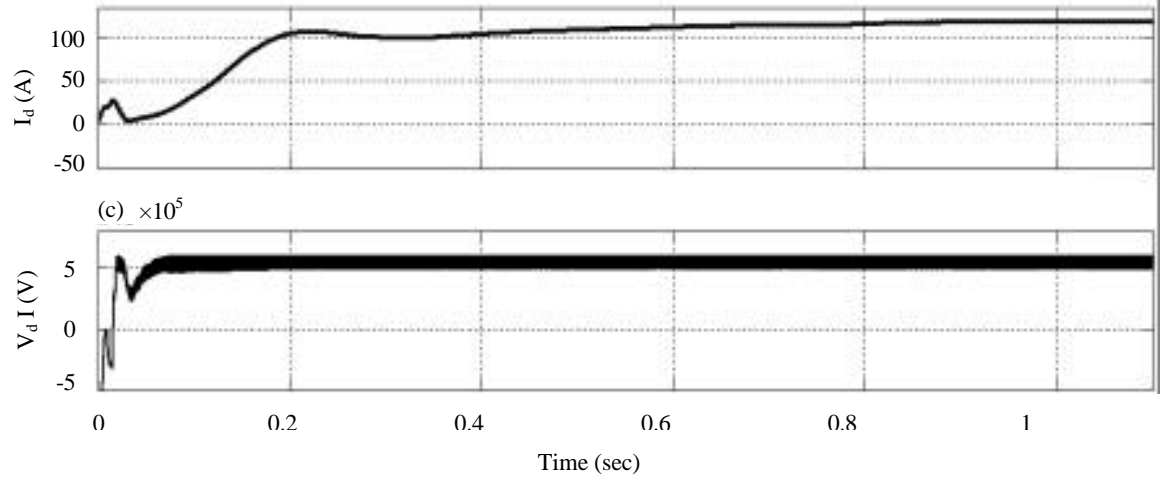

Fig. 7a-c): Rectifier DC voltage, DC current and inverter DC voltage with a solar irradiance of $1000 \mathrm{~W} / \mathrm{m}^{2}$, wind speed of $9.5 \mathrm{msec}, \alpha=30^{\circ}$ and $\gamma=150^{\circ}$

- Sudden change in $\gamma$ while the rest parameters are constant

- Sudden change in the PV irradiance while the rest parameters are constant

Owing to the serious effects of the changes of the $\mathrm{PV}$ irradiance or the wind speed on the generated power, a MPPT routines was utilized for both power resources. For each test case, the readings of the grid, the HVDC link, the PV output and the wind farm output were monitored and analyzed main title and author affiliation (Fig. 6-10).

Constant $\alpha, \gamma$, solar irradiance and wind speed: First, the system parameters were fixed with a constant $\alpha=30^{\circ}$, a constant $\gamma=150^{\circ}$, a wind speed $=9.5 \mathrm{~m} / \mathrm{sec}$ and a constant solar irradiance of $1000 \mathrm{~W} / \mathrm{m}^{2}$. The frequency of 


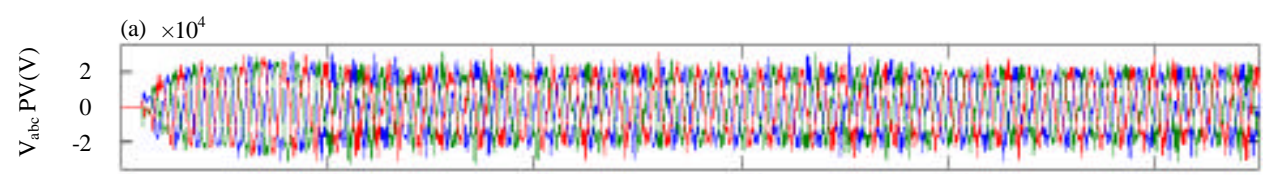

(b)
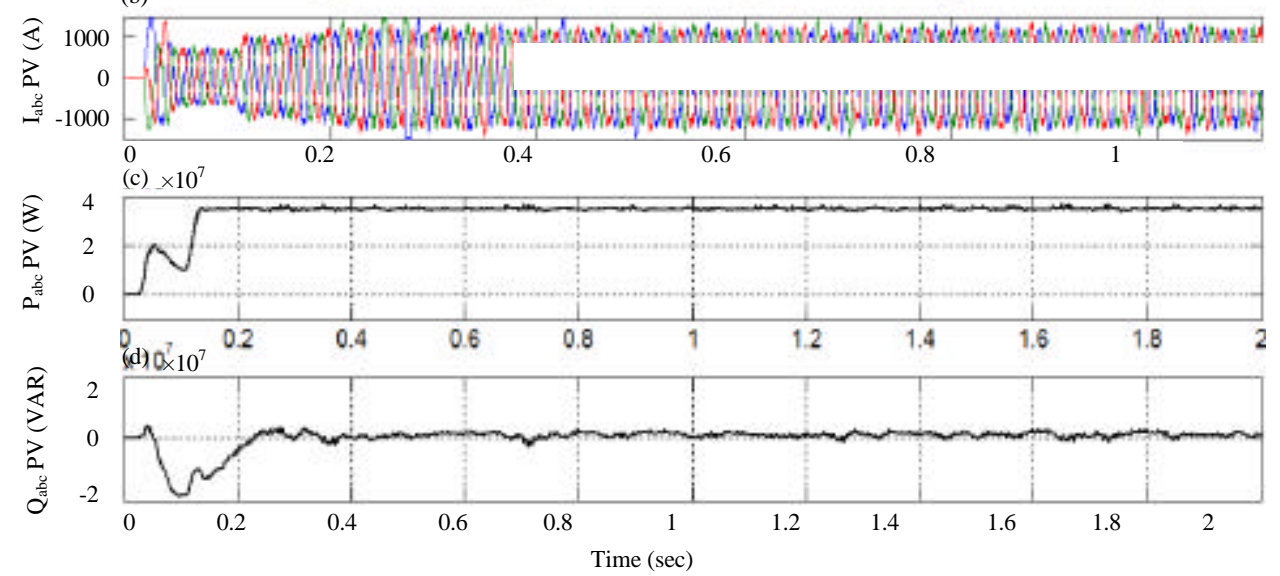

Fig. 8a-d): PV performance with a solar irradiance of $1000 \mathrm{~W} / \mathrm{m}^{2}$, wind speed of $9.5 \mathrm{msec}, \alpha=30^{\circ}$ and $\gamma=150^{\circ}$
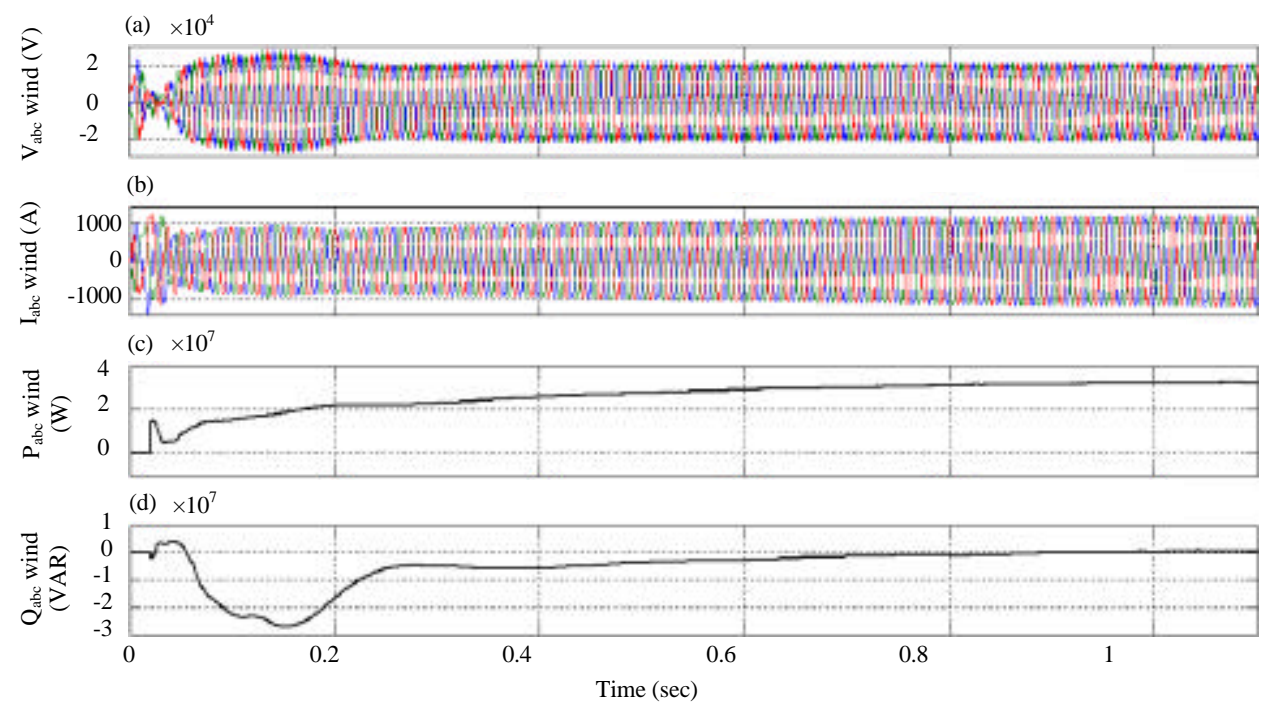

Fig. 9a-d): Wind performance with a solar irradiance of $1000 \mathrm{~W} / \mathrm{m}^{2}$, wind speed of $9.5 \mathrm{msec}, \alpha=30^{\circ}$ and $\gamma=150^{\circ}$

the rectifier station (both wind system and PV system) was set to $50 \mathrm{~Hz}$ whereas the frequency of the inverter station (grid side) was set to $60 \mathrm{~Hz}$. The MPPT routine of PV system was initiated after $0.4 \mathrm{sec}$. The resulting waveforms for the corresponding voltages, currents, active and reactive power were demonstrated in Fig. 6 for the grid. The measured DC voltage and current of the HVDC link was demonstrated in Fig. 7 having a DC voltage of $535 \mathrm{kV}$ with approximated current of $140 \mathrm{~A}$. Figure 8 emphasized the performance of the PV system with showing the three phase voltages at the $22 \mathrm{kV}$ level and its corresponding active/reactive power. Figure 9 emphasized the performance of the wind system showing the three phase voltages at the $22 \mathrm{kV}$ level and its corresponding active/reactive power. The variation of the resulting active power at different points of the simulated system was demonstrated in Fig. 10. As noted, the power at the gird side was reduced by the amount of the losses in the converter stations, the boost converter, the PV converter and the DC line (Fig. 11-18).

A sudden change of $\alpha$ with constant solar irradiance, wind speed and $\boldsymbol{\gamma}$ : In order to investigate the effects of controlling the extinction angle of the inverter station, $\alpha$ was 

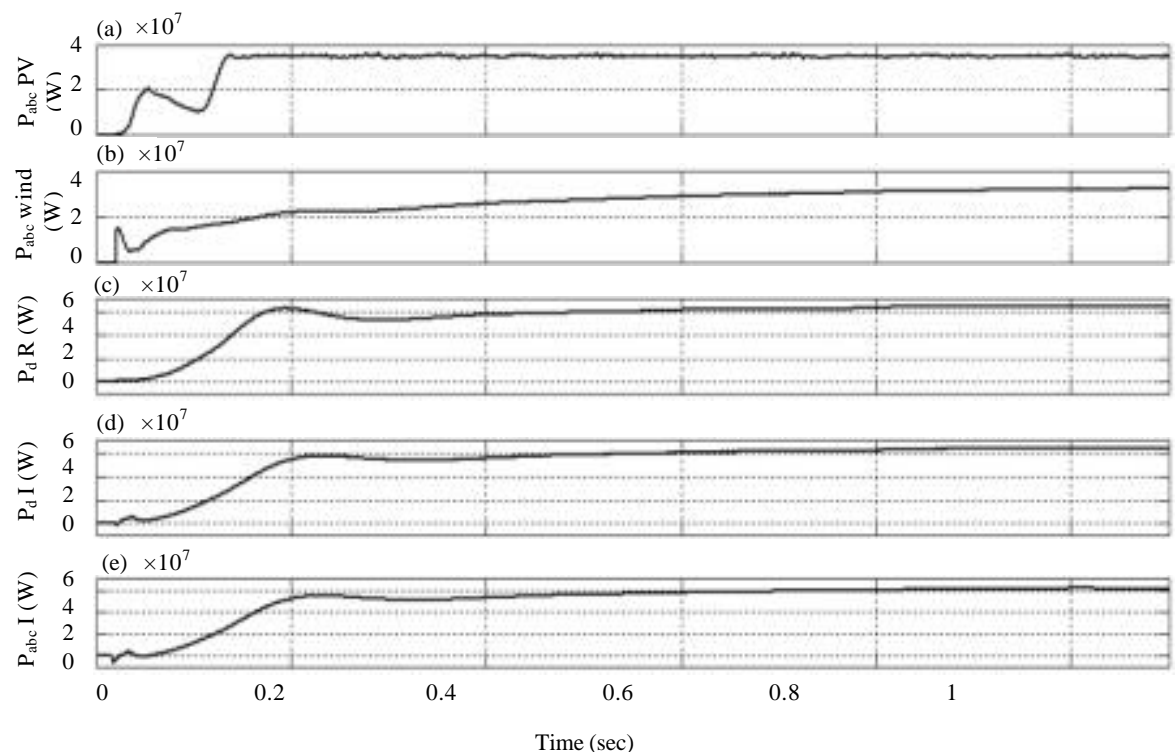

Fig. 10a-e): Measured power variation at overall system with a solar irradiance of $1000 \mathrm{~W} / \mathrm{m}^{2}$, wind speed of $9.5 \mathrm{msec}, \alpha$ $=30^{\circ}$ and $\gamma=150^{\circ}$
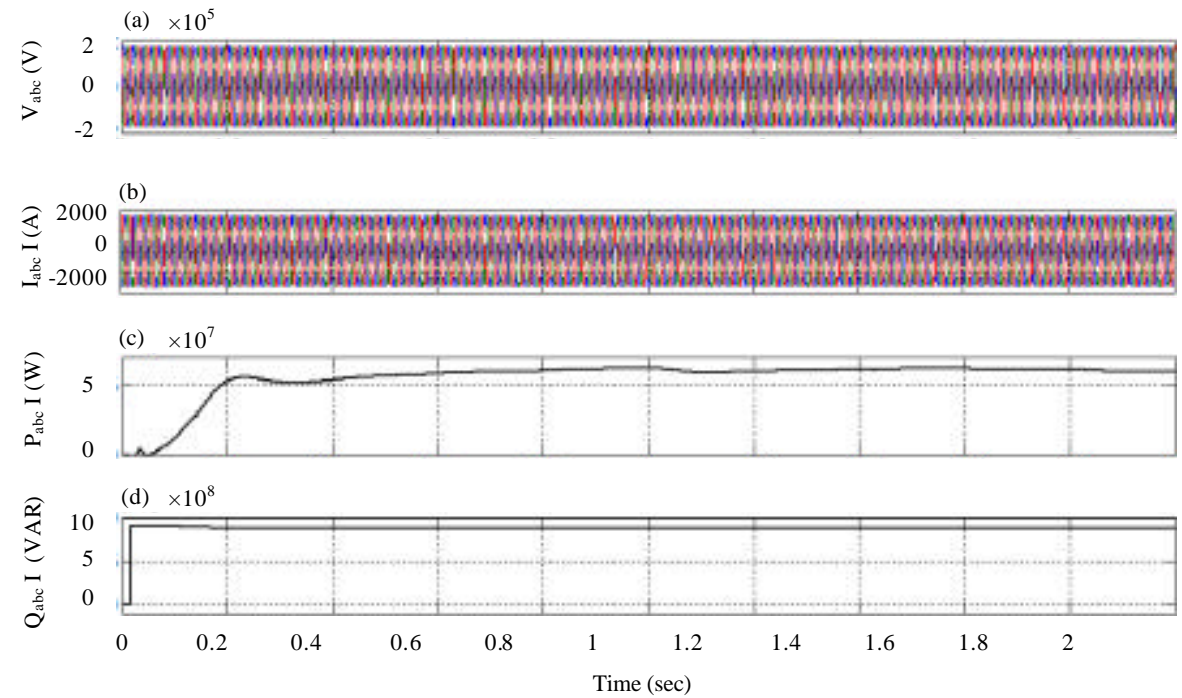

Fig. 11a-d): Grid side performance for a sudden change of $\alpha$ from $30-40^{\circ}$ with constant solar irradiance, wind speed and $\gamma$
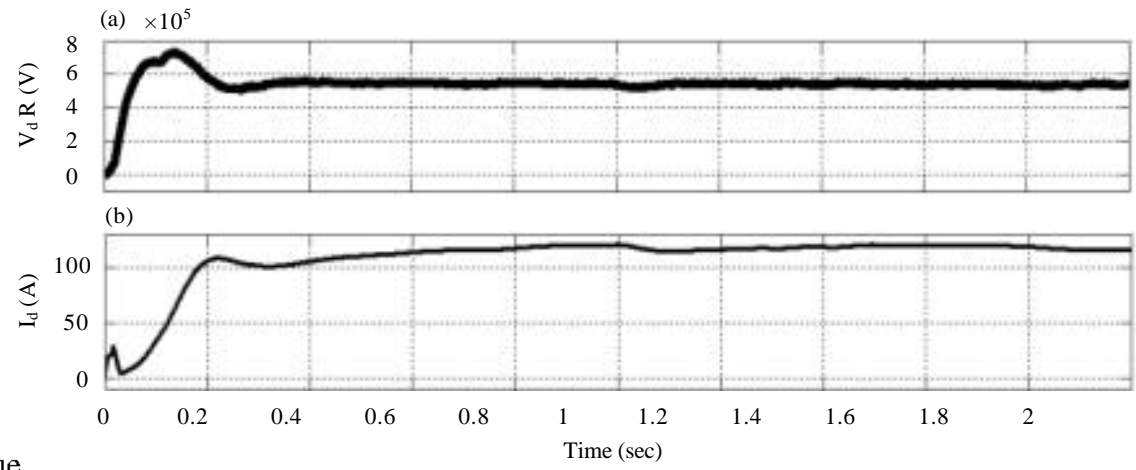

Fig. 12: Continue 


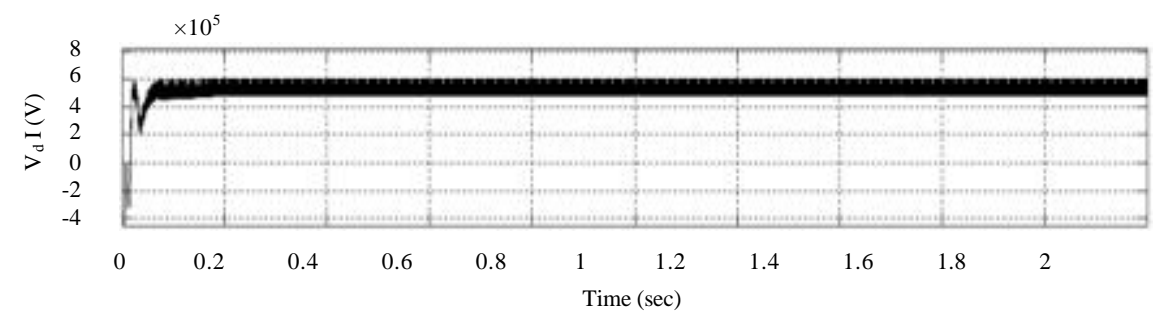

Fig. 12a-c): Performance HVDC link for a sudden change in a from $30-40^{\circ}$ with constant solar irradiance, wind speed and $\mathrm{g}$
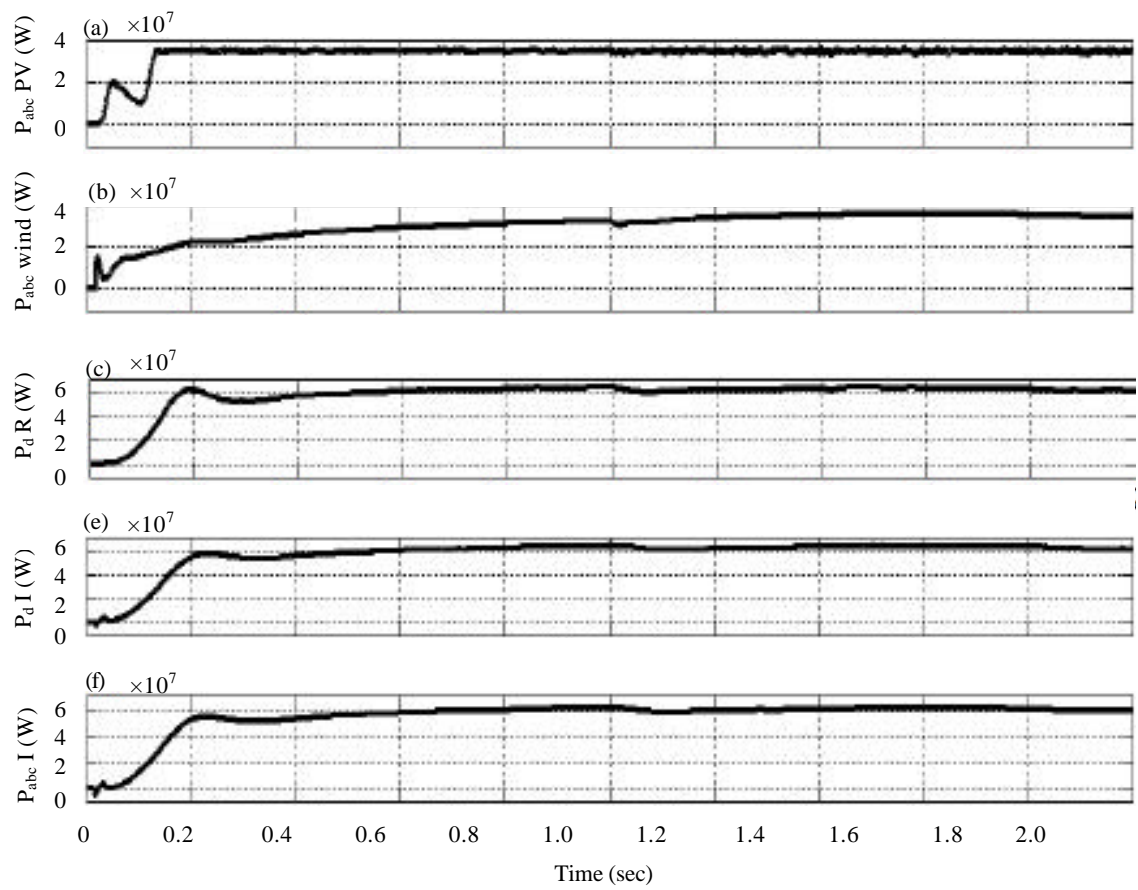

Fig. 13a-f): Power measurement for a suddden change in $\alpha$ from $30-40^{\circ}$ with constant solar irradiance, wind speed and $\gamma$
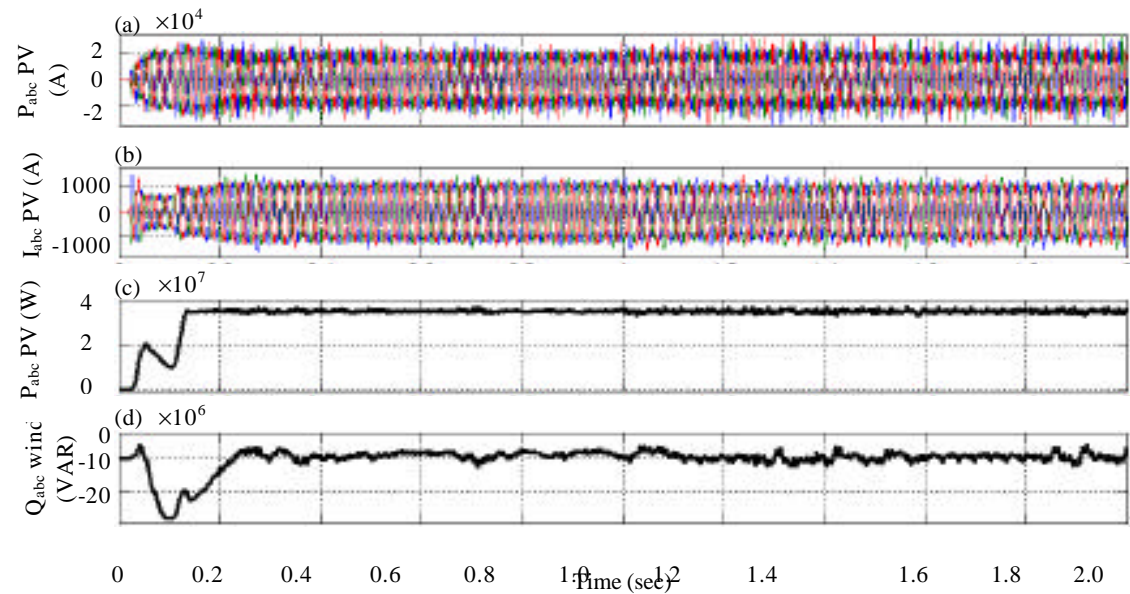

Fig. 14a-d): Performance of PV system for a sudden change in $\alpha$ from $30-40^{\circ}$ with constant solar irradiance, wind speed and $\gamma$ 

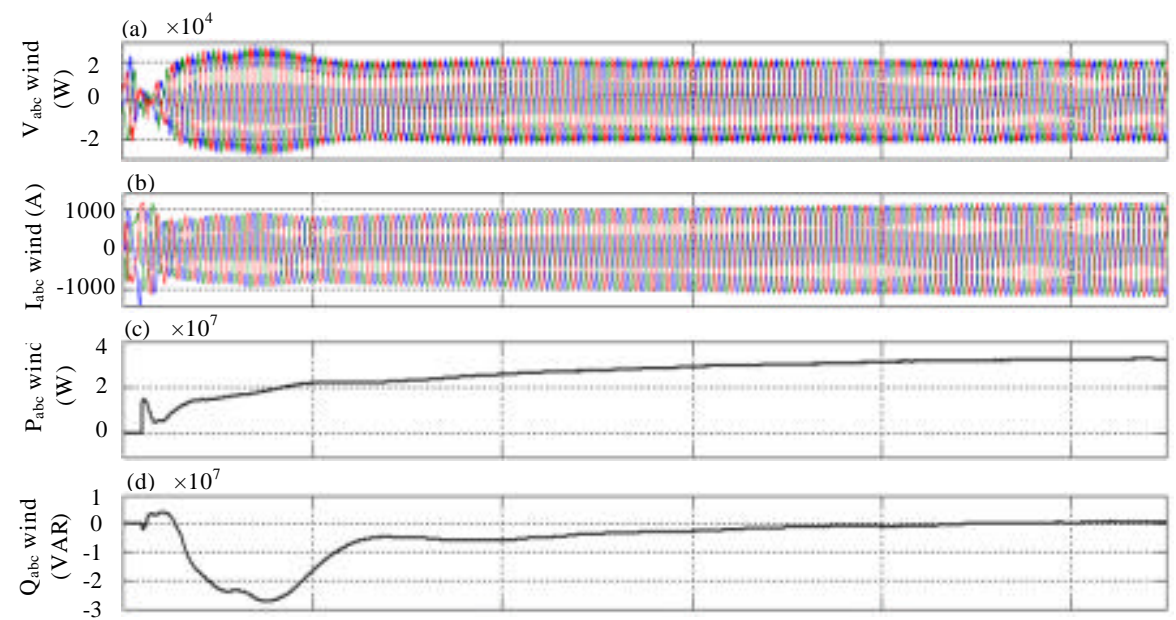

Time (sec)

Fig. 15a-d): Performance of wind system for a sudden change in $\alpha$ from $30-40^{\circ}$ with constant solar irradiance, wind speed and $\gamma$
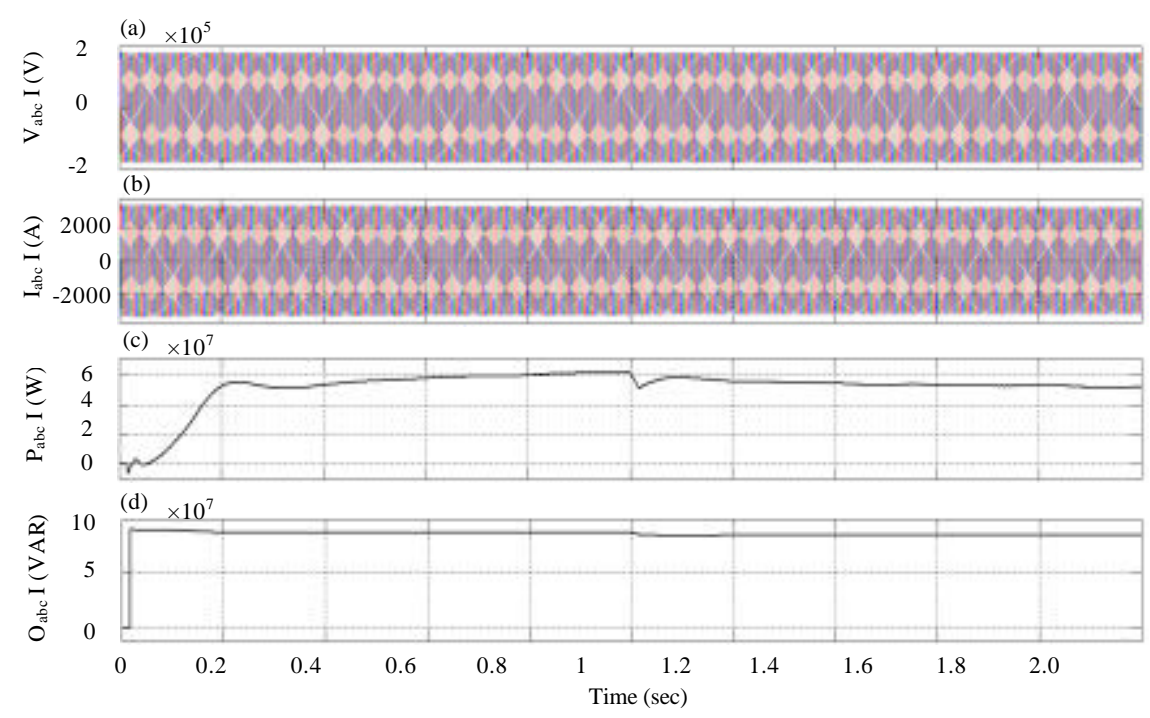

Fig. 16a-d): Grid side performance for a sudden change of $\alpha$ from $150-135^{\circ}$ with constant $\alpha$, solar irradiance and wind speed
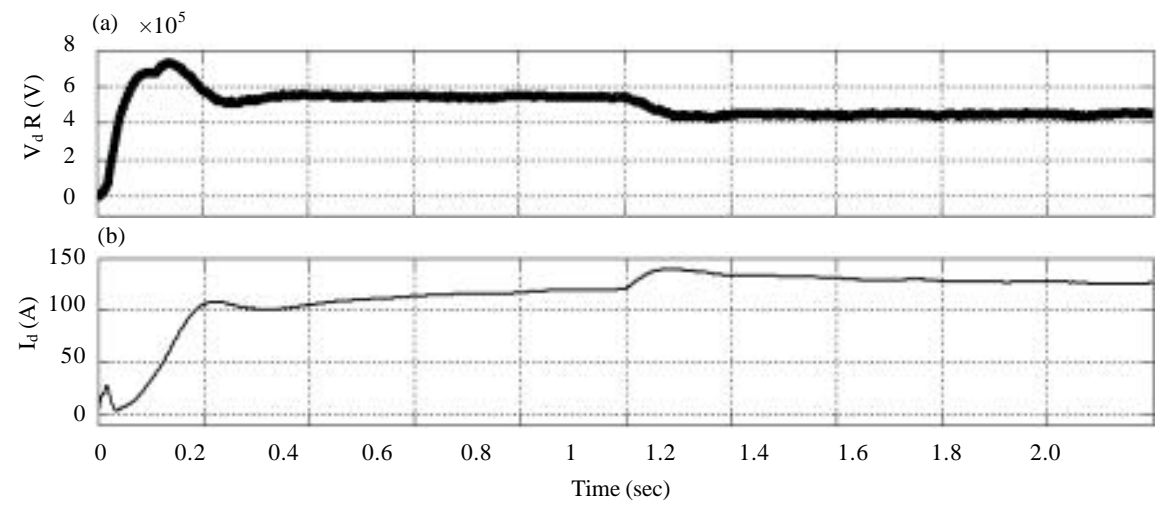

Fig. 17: Continue 


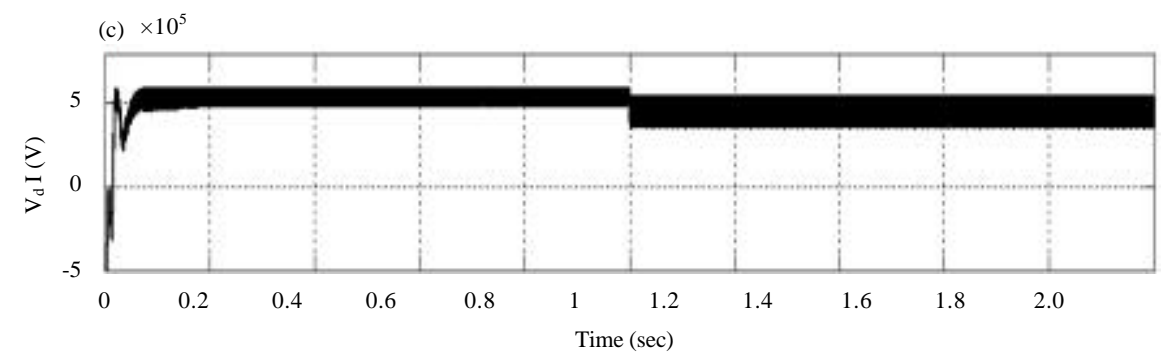

Fig. 17a-c): HVDC link performance for a sudden change of $\alpha$ from $150-135^{\circ}$ with constant $\alpha$, solar irradiance and wind speed
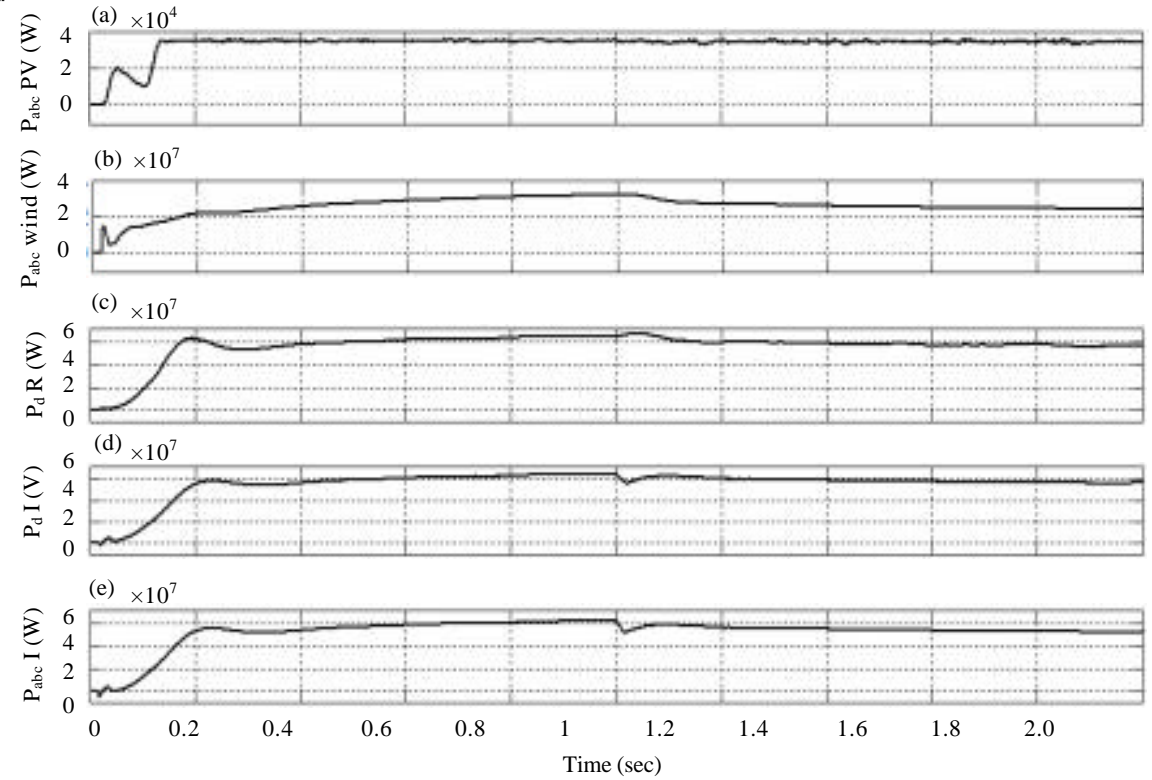

Fig. 18a-e): Power measurement for a sudden change in $\alpha$ from $150-135^{\circ}$ with constant $\alpha$, solar irradiance and wind speed
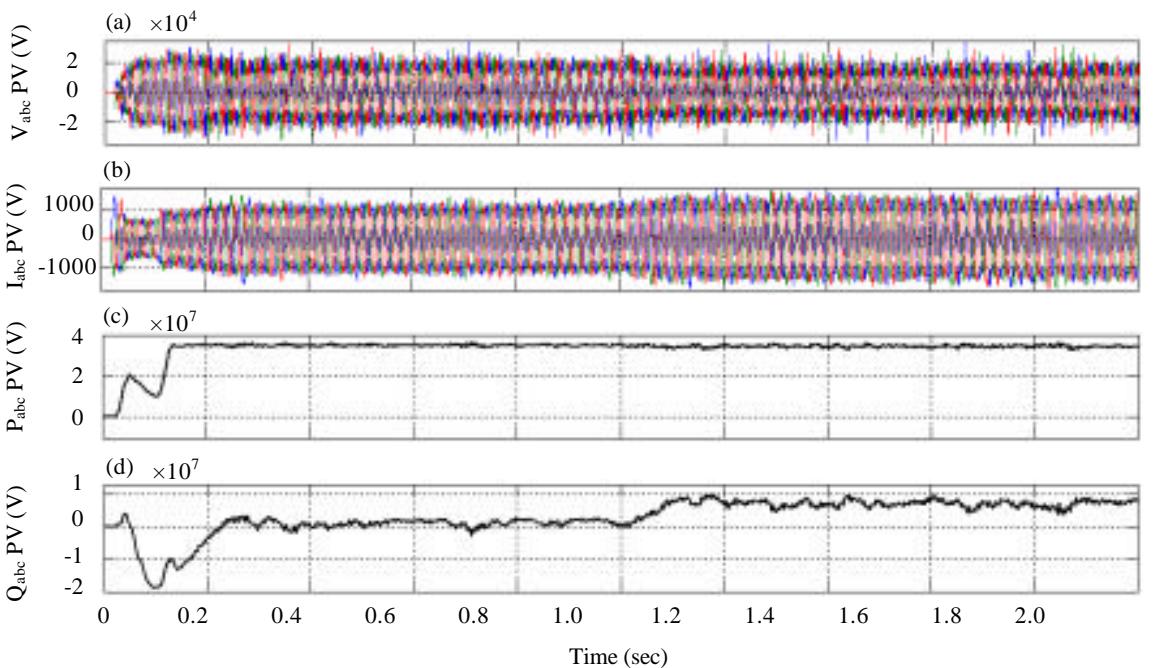

Fig. 19a-d): Performance of PV system for a sudden change in $\alpha$ from $150-135^{\circ}$ with constant $\alpha$, solar irradiance and wind speed

suddenly changed at $1 \mathrm{~s}$ from $30-40^{\circ}$ while keeping the solar irradiance, wind speed and the angle $\gamma$ constant at 1000 $\mathrm{W} / \mathrm{m}^{2}, 9.5 \mathrm{sec}$ and $150^{\circ}$, respectively. Figure 11 demonstrated the grid performance during this condition where both voltages and currents were almost constant. 

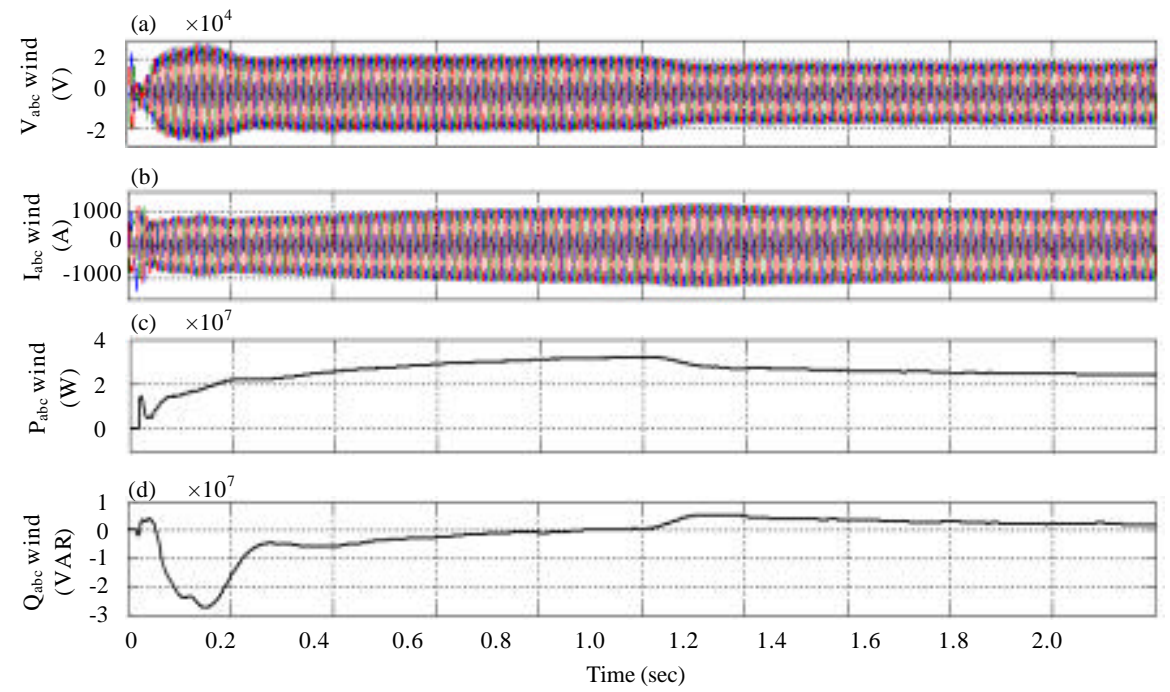

Fig. 20a-d): Performance of wind system for a sudden change in $\alpha$ from $150-135^{\circ}$ with constant $\alpha$, solar irradiance and wind speed
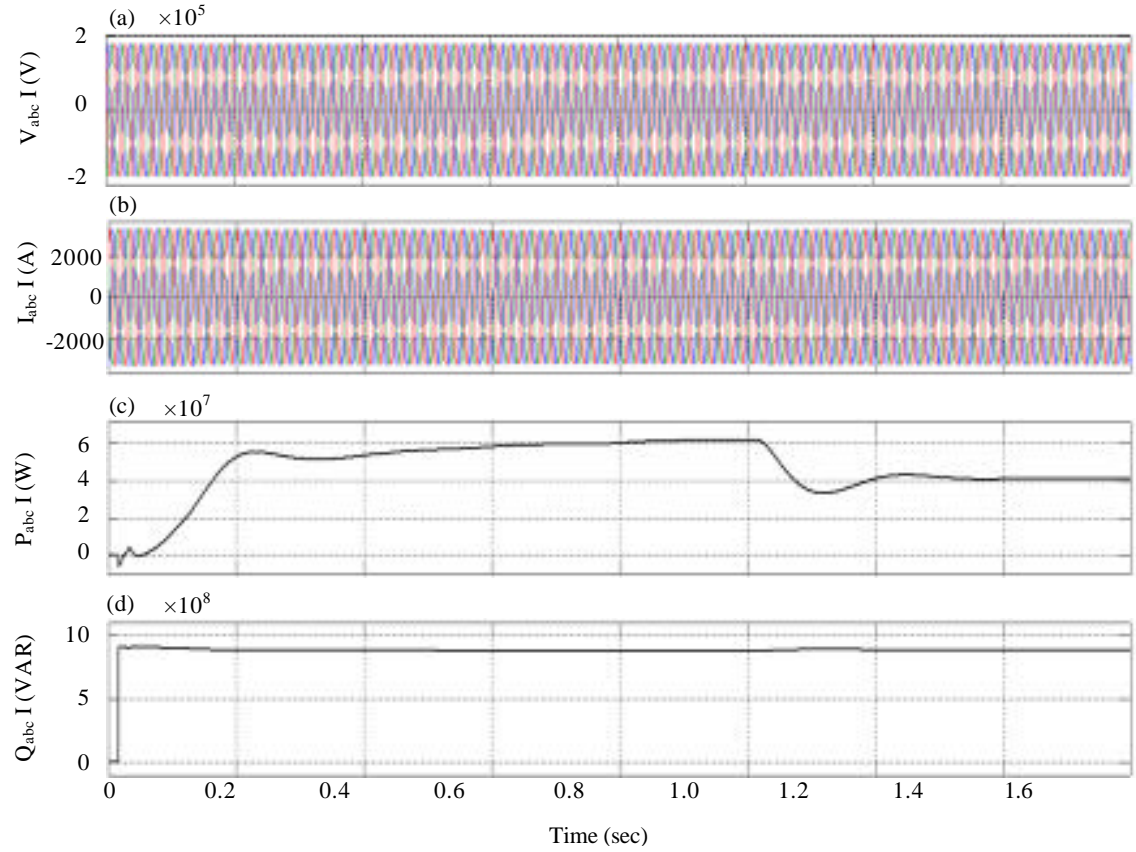

Fig. 21a-d): Grid side performance for a sudden change of solar irradiance from $1000 \mathrm{~W} / \mathrm{m}^{2}-400 / \mathrm{m}^{2}$ with constant $\alpha$, $\gamma$ and wind speed

On the other hand, the resulting active power was slightly reduced as a function of the firing angle $\alpha$. Figure 12 shows the performance of the HVDC link where the DC voltages at the inverter stations is not changed. However, the DC current and DC voltage at the rectifier were reduced depending on the value of firing angle $\alpha$. This, therefore, affects the measured power at the rectifier station, inverter station and the grid as shown in Fig. 13-15.
A sudden change of $\gamma$ with constant $\alpha$, solar irradiance and wind speed: In order to investigate the effects of controlling the extinction angle of the inverter station, $\gamma$ was suddenly changed at a time equal to $1 \mathrm{~s}$ from $150-135^{\circ}$ while keeping $\alpha$, the solar irradiance and wind speed constant at $30^{\circ}, 1000 \mathrm{~W} / \mathrm{m}^{2}$ and $9.5 \mathrm{sec}$, respectively. Figure 16 shows the grid performance during this condition where both voltages and currents were 

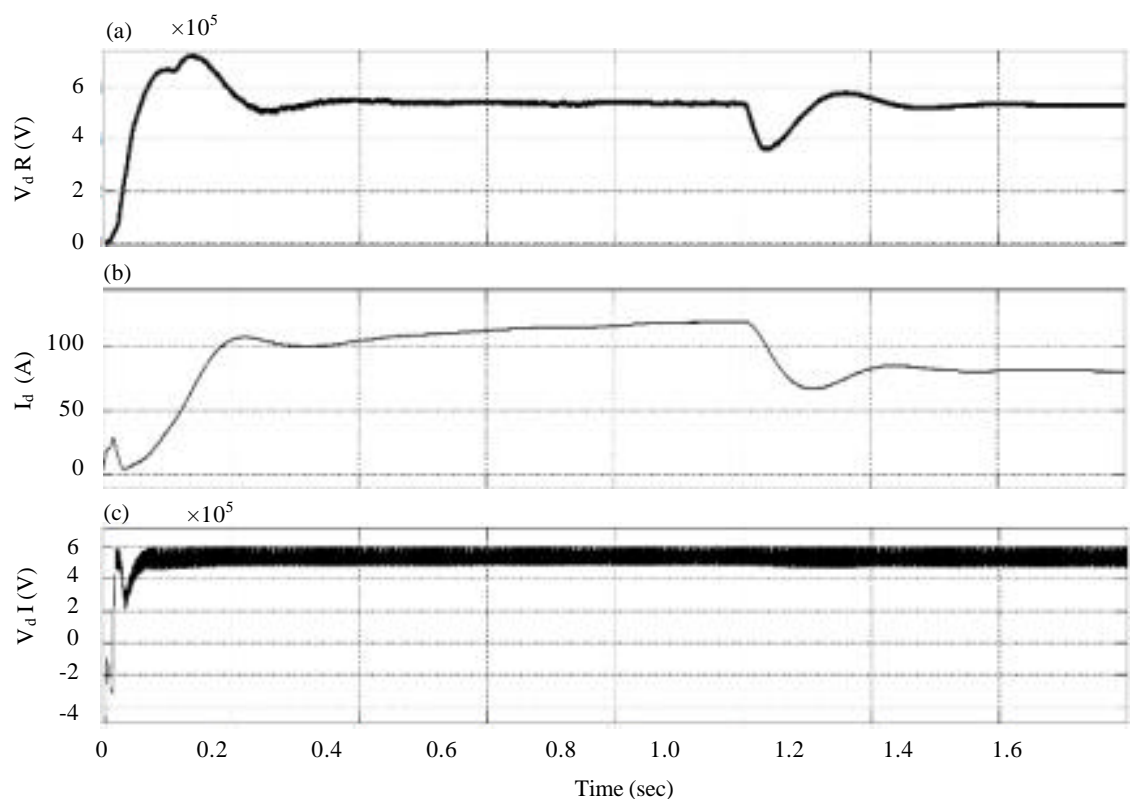

Fig. 22a-c): HVDC link performance for a sudden change of solar irradiance from $100 \mathrm{~W} / \mathrm{m}^{2}-400 / \mathrm{m}^{2}$ with constant $\alpha, \gamma$ and wind speed
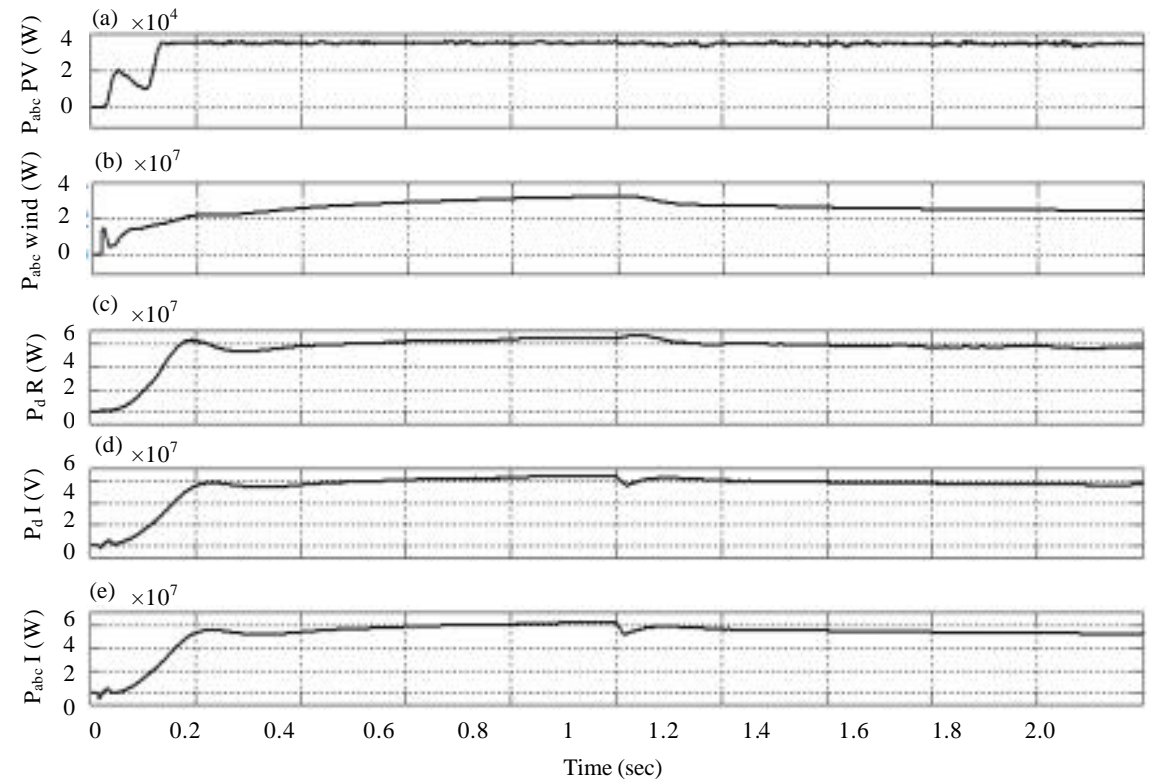

Fig. 23a-e): Power measurement for a sudden change in solar irradiance from $100 \mathrm{~W} / \mathrm{m}^{2}-400 / \mathrm{m}^{2}$ with constant $\alpha$, $\gamma$ and wind speed

almost constant. On the other hand, the resulting active power was slightly reduced as a function on the extinction angle $\gamma$.

Figure 17 shows the performance of the HVDC link where both voltages at rectifier and inverter stations were changed. However, the DC current is increased depending on the value of firing angle $\gamma$. This, therefore, affects the measured power at the rectifier station, at the inverter station and the grid side as shown in Fig. 18.
The resulting reactive power from the PV system was affected as illustrated in Fig. 19. Also, a remarkable distortion of the resulting AC voltage and current was noted revealing extra distortion contents. The active power was not affected as well. Whereas, the voltages, currents, active and reactive powers of the wind sub-system were affected as illustrated in Fig. 20. As concluded from the aforementioned results when the extinction angle $\gamma$ of the inverter station is changed, the 


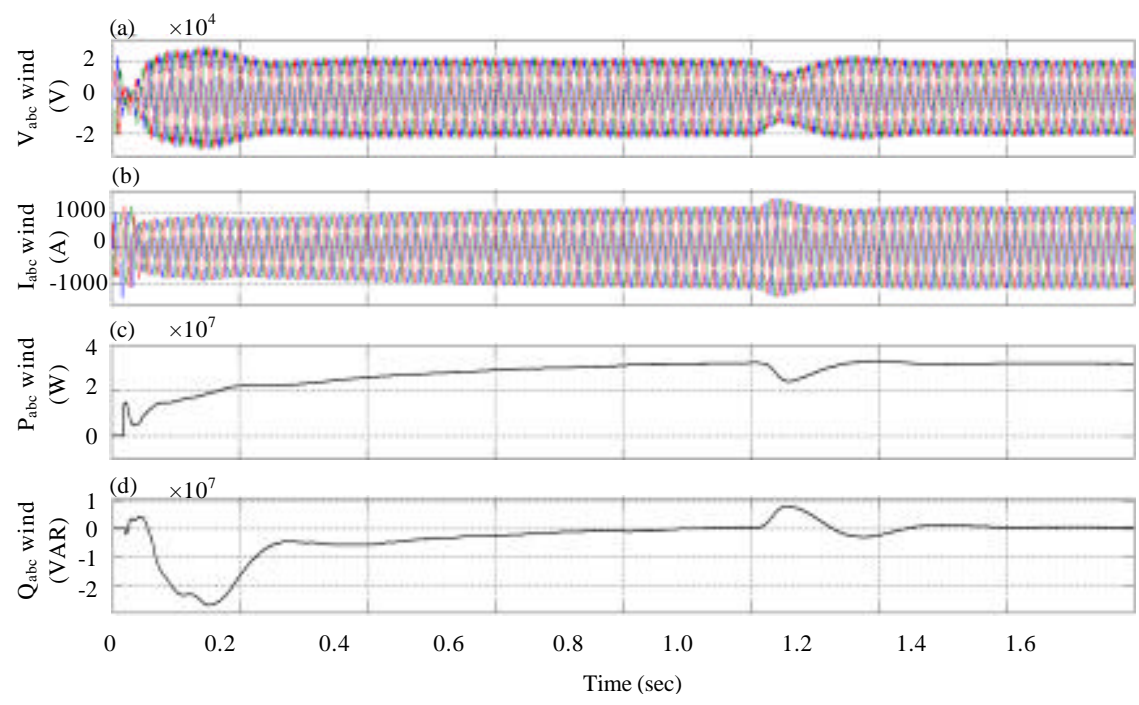

Fig. 24a-d): Performance of wind side for a sudden change of solar irradiance from $1000 \mathrm{~W} / \mathrm{m}^{2}-400 / \mathrm{m}^{2}$ with constant $\alpha, \gamma$ and wind speed
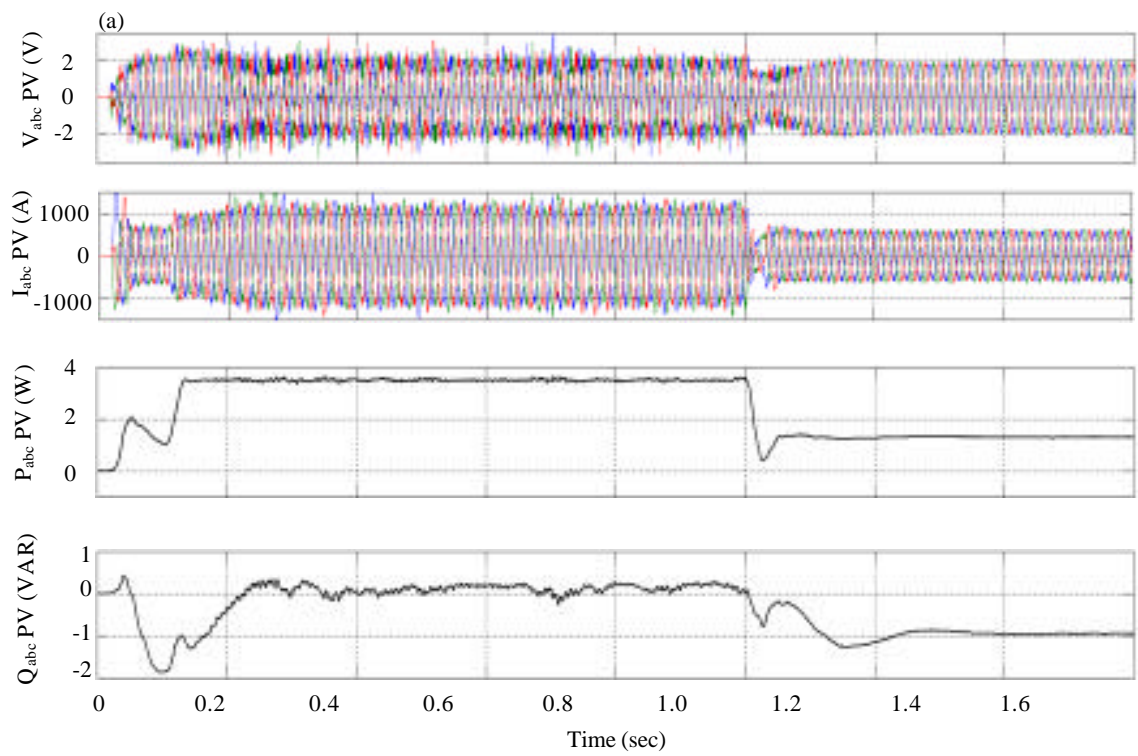

Fig. 25a-d): Performance of PV system for a sudden change of solar irradiance from $1000 \mathrm{Wm} \mathrm{W}^{2}-400 / \mathrm{m}^{2}$ with constant $\alpha$, $\gamma$ and wind speed

reactive power of both the PV and wind sub-systems have been affected and the corresponding output voltage of the rectifier station changes.

A sudden change of solar irradiance with constant $\alpha, \gamma$ and wind speed: In order to investigate the effects of solar irradiance on the system performance, the solar irradiance was suddenly changed at time $=1 \mathrm{sec}$ from 1000 $400 \mathrm{~W} / \mathrm{m}^{2}$ while keeping $\alpha, \gamma$ and wind speed constant at $30,150^{\circ}$ and $9.5 \mathrm{sec}$, respectively. Figure 21 shows the grid performance during this condition where the voltages and currents and reactive power were almost constant. On the other hand, the resulting active power was reduced as a output of PV reduced. Figure 22 shows the performance of the HVDC link where the corresponding DC voltage at the rectifier was decreased to its first values depending on time constant of the system. Whereas the DC voltage of the inverter side was not changed. However, the DC current was decreased depending on the PV power level. This, therefore, affects all measured power except the power of wind system that return to origin power level as shown in Fig. 23-25. 
All resulting voltages, currents, active and reactive powers of the wind sub-system were temporarily affected and restored to its origin state as illustrated in Fig. 24 whereas the corresponding outputs of the PV sub-system were affected as illustrated in Fig. 25.

\section{CONCLUSION}

In this study, integrating large scale PV power plants in conjunction with wind farms into the power grid via. a HVDC links was explored. Different benefits are gained using this integration methodology including eliminating the stability issues, higher capacity, lower losses, better voltage profile and better controllability. As noted, utilizing multiterminal bipolar-HVDC link facilitates integrating different $\mathrm{PV}$ units and wind units together to the grid with different frequencies $(50 \mathrm{~Hz}$ at the rectifier station and $60 \mathrm{~Hz}$ at the inverter station. Different investigation tests were applied including the variations of the firing angle of the rectifier station, extinction angle and the inverter station and solar irradiance. The MPPT routines were utilized successfully for maximizing the performance of large grid PVs and wind power plants. Controlling the firing angles of the converter and inverter $(\alpha$ and $\gamma$ ) helps supervising the integration profile effectively.

\section{ACKNOWLEDGEMENT}

The research would like to thank Deanship of Scientific Research at Umm Al-Qura University (UQU), Saudi Arabia for the financial Support (Project ID: 43408007).

\section{APPENDIX}

PV string (32 kW): The type of the module: sun-power SPR-30 SWHT.

Number of cells per module: 96

Number of series-connected modules per string: 35

Number of parallel strings: 330

\section{Manufacturer specifications for one module are:}

- Number of series-connected cells $=96$

- Open-circuit Vltage: $\mathrm{V}_{\mathrm{oc}}=64.2 \mathrm{~V}$

- Short-circuit current: $\mathrm{I}_{\mathrm{sc}}=5.96 \mathrm{~A}$

- Voltage and current at maximum power $: \mathrm{V}_{\mathrm{mp}}=54.7 \mathrm{~V}$ and $\mathrm{I}_{\mathrm{mp}}=5.58 \mathrm{~A}$

Wind turbine data: Induction generator parameter:

- $\mathrm{P}=660 \mathrm{~kW}, \mathrm{~V}=690 \mathrm{~V}, \mathrm{~F}=50 \mathrm{~Hz}$, speed $1500 \mathrm{rpm}$

- $\mathrm{R}_{\mathrm{s}}=0.016 \mathrm{pu}, \mathrm{L}_{l s}=$ Leakage inductance of the stator $=0.06 \mathrm{pu}$
- $\mathrm{R}_{\mathrm{r}}{ }^{\prime}=$ Rotor resistance referred to stator, $0.015 \mathrm{pu}, \mathrm{L}_{\mathrm{lr}}{ }^{\prime}$ $=$ Leakage inductance of the rotor referred to stator $=$ $0.06 \mathrm{pu}, \mathrm{L}_{\mathrm{m}}=$ Mgnetizing inductance $=3.5 \mathrm{pu}$

- inertia constant $=3.5 \mathrm{pu}$, No. of pole $=4$

\section{Turbine data:}

- Nominal wind turbine mechanical output power $=600 \mathrm{~kW}$

- $\quad$ Base wind speed $=9.5 \mathrm{~m} / \mathrm{sec}$

- Maximum power at base wind speed (pu of nominal mechanical power $)=1 \mathrm{pu}$

- Base rotational speed (pu of base generator speed) $=1 \mathrm{pu}$

- Pitch angle controller gain $\left(\mathrm{K}_{\mathrm{p}}, \mathrm{K}_{\mathrm{i}}\right)=5,25$

- Maximum pitch angle $=45^{\circ}$ and maximum rate of change of pitch angle $=2^{\circ}$

- Self excited capacitance of each induction generator $=75 \mathrm{kVAR}$

\section{REFERENCES}

Ackermann, T., 2005. Wind Power in Power Systems. John Wiley and Sons, New York, USA., ISBN-13: 9780470012673, Pages: 742.

Ahmed, S., G. Sowilam and M. Abdelkader, 2005. Comparison study between three phase three level inverter techniques. Proceedings of the 10th International Conference on Middle East Power System (MEPCON2005), December 13-15, 2005, Port Said, Egypt, pp: 353-362.

Alatrash, H., Amarin, R.A. and C. Lam, 2012. Enabling large-scale PV integration into the grid. Proceedings of the 2012 IEEE International Conference on Green Technologies, April 19-20, 2012, IEEE, Tulsa, Oklahoma, USA., ISBN:978-1-4673-0968-4, pp: 1-6.

Carbone, R., 2009. Grid-connected photovoltaic systems with energy storage. Proceedings of the 2009 International Conference on Clean Electrical Power (ICCEP-2009), June 9-11, 2009, IEEE, Capri, Italy, ISBN:978-1-4244-2543-3, pp: 760-767.

Da Rosa, A.V., 2009. Fundamentals of Renewable Energy Processes. 2nd Edn., Elsevier Inc., Amsterdam, Netherlands, USA., ISBN:9780080878232, Pages: 864.

Gao, B., R. Zhang, R. Li, H. Yu and G. Zhao, 2017. Subsynchronous torsional interaction of wind farms with FSIG wind turbines connected to LCC-HVDC lines. Energies, 10: 1-18.

Hosseini, S.H., F. Nejabatkhah, S. Danyali and S.K.M. Niapour, 2011. Grid-connected three-input $\mathrm{PV} / \mathrm{FC} /$ Battery power system with active power filter capability. Proceedings of the 2011 2nd IEEE PES International Conference and Exhibition on Innovative Smart Grid Technologies, December 5-7, 2011, IEEE, Manchester, UK., ISBN:978-1-4577-1422-1, pp: 1-7. 
Karlis, A. and P. Dokopoulos, 1996. Small power systems fed by hydro, photovoltaic, wind turbines and diesel generators. Proceedings of the 3rd International Conference on Electronics, Circuits and Systems Vol. 2, October 16-16, 1996, IEEE, Rodos, Greece, ISBN:0-7803-3650-X, pp: 1013-1016.

Markvart, T. and L. Castaner, 2003. Practical Handbook of Photovoltaics: Fundamentals and Applications. 1st Edn., Elsevier, Oxford, ISBN: 1856173909 .
Rashid, M.H., 2001. Power Electronics Handbook. 2nd Edn., Academic Press, Cambridge, Massachusetts, USA., ISBN:9780125816502, Pages: 895.

Sowilam G., M.I. ELkorfolly and A.R. Younis, 2014. Operation and control of wind farm interconnected to grid using LCC bipolar HVDC link. Intl. J. Artif. Intell. Syst. Mach. Learn., 6: 85-91.

Yao, J., L. Guo, T. Zhou, D. Xu and R. Liu, 2017. Capacity configuration and coordinated operation of a hybrid wind farm with FSIG-based and PMSG-based wind farms during grid faults. IEEE. Trans. Energy Conver., 32: 1188-1199. 